\title{
Formas do conto romântico no Brasil: a prosa poética de "Carlotinha da mangueira", de Gentil Braga
}

Maria Cecília Boechat Universidade Federal de Minas Gerais

\begin{abstract}
Resumo: Análise da narrativa "Carlotinha da mangueira", de autoria do poeta maranhense Gentil Homem de Almeida Braga, tendo em vista $o$ uso de procedimentos poéticos. O breve comentário visa, ainda, a indicar a possibilidade de reconhecimento da existência de uma tradição propriamente romântica na história do conto moderno brasileiro.

Palavras-chave: Literatura brasileira, Conto romântico, "Carlotinha da mangueira".
\end{abstract}

Embora a tendência de estudiosos do conto brasileiro seja a de situar sua configuração propriamente literária somente no decênio de 1880, com a publicação de Papéis avulsos, de Machado de Assis (1882), ${ }^{1}$ a existência histórica do conto moderno brasileiro é, reconhecidamente, bastante anterior a essa baliza. Muitos foram os autores nacionais que publicaram (ao lado de

1. Cf. LIMA. Variações sobre o conto, p. 71; MONTELLO. O conto brasileiro: de Machado de Assis a Monteiro Lobato, p. 13; LIMA SOBRINHO. Os precursores do conto no Brasil, p. 9. 
traduções e adaptações de autores estrangeiros) nas páginas dos vários periódicos que circularam no Brasil oitocentista e de modo particularmente intenso desde o final de 1830. Trata-se de uma produção sabidamente numerosa e variada, mas pouco conhecida e frequentada, encontrando-se, em sua maior parte, dispersa nos jornais da época, ainda à espera do esforço de reunião e reedição.

Entretanto, se o acesso é difícil e parcial, existe, à disposição do pesquisador, um conjunto importante de obras de referência. Desse acervo, merecem destaque os dois primeiros volumes da coleção "Panorama do conto brasileiro", publicada pela editora Civilização Brasileira, por se tratar da primeira tentativa de reunião - sendo, ainda hoje, a mais completa, em termos de variedade de autores e amplitude temporal - da extensa produção ficcional em prosa de contistas que, anteriores a Machado de Assis, firmaram o que agora podemos reconhecer como uma tradição continuada de prosa ficcional no Brasil.

A despeito da separação do material em dois volumes - o primeiro dedicado aos "precursores" do conto brasileiro, e o segundo, ao "conto romântico" -, a sugerir a distinção entre os dois tipos de narrativa, não é o que de fato ocorre no aparato crítico.

Assim é que, cobrindo o decênio de 1830 a 1840, o primeiro volume, Os precursores do conto no Brasil, com seleção e notas de Barbosa Lima Sobrinho, reúne textos de autores de pouco renome literário, em sua maioria jornalistas, como Justiniano da Rocha, Pereira da Silva, Josino Nascimento Silva, Firmino Rodrigues da Silva, Francisco de Paula Brito, Vicente Pereira de Carvalho Guimarães, Martins Pena, João José de Sousa e Silva Rio. Chamando a atenção para os interesses não propriamente literários desses autores, que "não eram, a rigor, vocações espontâneas", Barbosa Lima Sobrinho procura justificar a razão de ser de uma coletânea que, ao gosto de seus leitores, só poderia ser julgada péssima. Como afirma na Introdução:

Estamos apenas enumerando poemas, romances, novelas e contos, que apareceram nessa época a que nos reportamos. Decerto que o estudo e as conclusões seriam diferentes, se os subordinássemos a um critério ou preocupação de valor literário. Autor moderno não hesita em denominar "pífia" uma das novelas traçadas ao gosto romântico.

2. LIMA SOBRINHO. Os precursores do conto no Brasil, p. 22. 
O trecho é significativo, por mostrar que, se o critério histórico prevalece, enunciam-se também, aqui, pressupostos literários e críticos: antes de tudo, o conjunto dos textos selecionados sofre uma geral desqualificação estética, para, em seguida, ser identificado como "romântico" (e não como pertencente a um período anterior, ou "precursor", como anunciado pelo título do volume).

O segundo volume da coleção, O conto romântico, embora a cargo de outros organizadores (a seleção é de Edgard Cavalheiro, que não chegou a publicar o volume, tarefa que coube a Mário da Silva Brito, responsável também pela Introdução e pelas notas), reúne textos publicados a partir da década de 1840, cobrindo as fases definidas por Barbosa Lima como as de "afirmação do romantismo" (1840-1850) e "apogeu do romantismo" (1850-1861), embora estenda o último período, com a apresentação de narrativas publicadas na década de 1870.

Apesar de supostamente lidar com um material mais qualificado, apresentando textos de prosadores como Joaquim Manuel de Macedo, José de Alencar e Bernardo Guimarães, essa não é a opinião dos organizadores, que se perfilam nitidamente ao lado de Barbosa Lima, no que diz respeito à atribuição de valor intrinsecamente histórico-cultural ao conjunto dos textos selecionados:

Nem sempre essas peças são do nosso agrado, em nenhum momento deixam de merecer a nossa compreensão e até respeito. É que representam uma etapa básica, experimental, abridora de caminhos [...]. Páginas primitivas, e tantas vezes falsas, senão ridículas, são também páginas de espírito, de devoção e de amor, de labor e constância, em busca de uma interpretação de nossa gente e de nosso comportamento.

Segue-se que o volume O conto romântico também seria, por sua vez, "precursor", no sentido de fundamentar e anunciar, historicamente, o advento da forma na prosa madura de Machado de Assis e seus desdobramentos posteriores:

Nela [nessa antologia] se sente a evolução do gênero, documenta-se o árduo esforço que o artista brasileiro desenvolveu para dominar o seu instrumento de expressão, evidenciam-se os erros e os defeitos que aproveitariam exemplarmente aos sucessores no trato da narrativa curta, enfim, está aí todo o processo histórico que fundamenta a prosa contida e concisa de

3. BRITO. Nota introdutória, p. 6-7. Escapam à desqualificação geral as narrativas de Machado de Assis e de Álvares de Azevedo, elogiadas no aparato crítico das coletâneas. 
Machado de Assis, a objetividade realista, a transfiguração simbolista, a invenção modernista, a plenitude contemporânea.

O movimento é duplo: embora o primeiro volume seja dedicado aos "precursores", acaba-se por classificá-los como "românticos"; vindo da outra ponta, o volume dedicado aos contistas românticos acaba por tomá-los como "precursores".

Perdido assim o critério organizador do material em dois volumes, perde-se também a visão mais filigranada do conjunto de nossa primeira prosa ficcional (definida, agora, em bloco, como aquela anterior à segunda fase da prosa de Machado de Assis). Ora, cobrindo um amplo arco temporal e uma grande gama de autores, é de se esperar, por princípio, que os dois volumes reúnam realizações bastante díspares, seja em termos de visão de mundo, seja em termos de refinamento no uso de técnicas narrativas, e, portanto, esteticamente diversas. O desdobramento lógico indica, então, a possibilidade de demonstrar a existência, no conjunto, de formas narrativas diversas ou, em outros termos, de distinguir "precursores" e "românticos".

A esse respeito, é importante retomar a "Nota introdutória" ao segundo volume, em que Mário da Silva Brito define o que os selecionadores entendem ser o conto romântico:

O conto, no romantismo, é incaracterístico, "uma coisa informe e vaga", como repara o próprio Edgard Cavalheiro. [...] Na verdade, o conto assumiria a sua estrutura de contensão e medida, muito tempo depois, com Machado de Assis, cujas produções iniciais, se bem que quase sempre superiores às de seus predecessores e até contemporâneos, ainda estão eivadas dos vícios da escola, e desbordam dos limites que o gênero exige. São exatamente esses vícios que impedem o florescimento de uma forma narrativa que repudia a prolixidade, a eloqüência, o excesso de imaginação, a fantasia, o sentimentalismo, as expansões derramadas, a exuberância de emoções e de linguagem. Tristão de Ataíde vê, nessa situação, o modo de explicar "a extrema pobreza de nosso conto romântico." É essa também a opinião de Edgard Cavalheiro. Para ele, tendo sido o romantismo essencialmente palavroso, sobrepondo o sentimento à razão, o entusiasmo ao raciocínio, o subjetivismo ao objetivismo, as generalizações imaginosas ao senso crítico, não ofereciam mesmo terreno propício ao conto, que impõe a síntese, que requer concentração, que implica no "pudor de dizer apenas

4. BRITO. Nota introdutória, p. 6. 
o necessário para poder insinuar tudo", como reparou o ensaísta Osmar Pimentel. Os românticos, temperamentos confessionais e escancarados, tagarelas e desprovidos do senso de ridículo eram, na realidade, os menos indicados para a reconstituição, breve e recatada, de fragmentos de vida, de episódios bem demarcados, de análises psicológicas de caracteres, de profundidade de observação, de desnudamento e revelação da alma humana. Foram todos, enquanto ficcionistas, superficiais e, muitos, fúteis e inconseqüentes. Tinham, da própria vida, essa concepção exterior, irrefletida, idealista e desbragada. Não se lhes negue, portanto, coerência e sinceridade na visão de arte e do mundo. Careciam, isso sim, de artifício, da malícia que preside à construção técnica da ficção.

O argumento é claro: definindo de modo tradicional o romantismo brasileiro - como uma poética de pura emoção, tecnicamente tosca, inconsciente e incontida -, fica estabelecida, desde o início e por princípio, a inaptidão de nossos escritores do período para a realização de uma forma literária como o conto, que se define justamente pela proporção reduzida, pelo senso de medida, enfim, pela unidade necessária à concentração muito própria dessa forma narrativa.

A narrativa de "Carlotinha da mangueira", de autoria do poeta maranhense Gentil Braga, é um dos casos que mostram a possibilidade (e a necessidade) de distinção entre o que seria uma narrativa "precursora" (ou pré-romântica) - com seu sentimentalismo "desbragado" e sua correspondente linguagem "derramada" - e o que já podemos reconhecer como um conto propriamente romântico - uma narrativa que, instaurando um distanciamento crítico em relação ao sentimentalismo, demonstra maior contenção no tratamento do tema e no uso da linguagem.

O próprio antologista, no texto de apresentação, não deixa de apreciar o traço da narrativa que ora nos interessa, ao se referir a ela como uma "historieta vazada em prosa poética [...] reveladora de certo cuidado de composição, na busca, esforçada, de uma cadência, de um ritmo, a denunciar, no prosador, o poeta”. ${ }^{6}$ Certamente, Mário da Silva Brito fundamenta seu juízo em dados biográficos do autor: Gentil Homem de Almeida Braga (1835-1876) foi poeta de renome, "considerado como o melhor poeta maranhense depois de Gonçalves Dias”, como informa na mesma apresentação.

5. BRITO. Nota introdutória, p. 6.

6. BRAGA. Carlotinha da mangueira, p. 111-112. 
Reelaborando a formulação, podemos pensar, antes, que essa busca, essa explícita e intencionada mistura de prosa e poesia em "Carlotinha da mangueira" cumpre um programa mais que "pessoal", um programa de "escola", digamos assim, propriamente romântico, em sua ruptura com uma das mais caras normas das preceptivas clássicas - a separação entre gêneros -, o que faz com que a narrativa se apresente como um texto francamente moderno no que diz respeito aos procedimentos narrativos adotados. Por outro lado, deve-se considerar, ainda, que os elementos poéticos intrincados na narrativa assumem, necessariamente, alguma função específica na dinâmica do texto.

O primeiro efeito do tratamento poético da linguagem consiste na dificuldade de exposição parafrásica do texto, o que torna particularmente difícil o comentário sobre o conto, que não apresenta um enredo propriamente dito trata-se de uma série de ações concatenadas no tempo e no espaço. Na verdade, muito pouca coisa "acontece" na narrativa, cuja regra de composição parece ser a criação de uma imagem - de uma menina (a Carlotinha do título) que passa, observada pelo narrador, encaminhando-se rumo à sombra de uma mangueira, em torno da qual gira três vezes e tenta abrir com os dedinhos um buraco no tronco imagem que se repete e que, enquanto retorna no texto, vai sendo complementada por informações que explicam esse estranho comportamento da personagem.

O que ficamos sabendo de seu passado daria páginas de um folhetim trágico: a menina, rica de berço, depois conheceu a miséria; empobrecido, o pai se suicidou; a mãe morreu louca no hospital e um irmão morreu naufragado. Contido, o narrador não explora esse enredo rocambolesco, dando-nos conta de todos esses acontecimentos funestos em apenas um parágrafo.

O motivo da mangueira também é revelado: passado o ano de luto, a menina começou a ter sonhos com o gênio da riqueza, que se apresenta a ela em sonhos como um pequeno boneco vestido de azul e com um barrete dourado na cabeça. Nos sonhos, ele canta uma cantiga, em que descreve seu lindo e farto reino, a que terá acesso quem conseguir apossar-se de seu barrete dourado; mas quem não o conseguir está destinado a abrir com os dedos, a muito custo, o tronco da mangueira para encontrar o anel brilhante com que o poderá prender. Após todas essas explicações, a narrativa finaliza revelando ser aquela a última vez em que se vê passar a menina, encontrada morta, ao nascer do sol, encostada ao tronco da mangueira. É quando (e somente quando) se enuncia claramente o sentido da narrativa: "No dia seguinte falava-se e dizia-se que Carlotinha, a doida, tinha cessado de sofrer".

7. BRAGA. Carlotinha da mangueira, p. 117. 
O desfecho da narrativa, apresentando essa explicação racional, reorganiza um conjunto de elementos aparentemente disparatado e incongruente e encaminha uma história até então tendente ao tipo maravilhoso para os domínios da racionalidade, o que insere a narrativa na categoria do estranho (tal como definida por Tzvetan Todorov, em que acontecimentos insólitos recebem uma explicação lógica). ${ }^{8}$ Nem "excesso de imaginação" nem "fantasia”, portanto, mas rigorosa verossimilhança realista.

Ainda assim, é preciso reconhecer que, em toda a extensão do texto, dominam a ilogicidade, a ambientação mágica e a recusa da referencialidade, podendo-se dizer que a singularidade do modo de construção da narrativa consiste justamente na adoção de uma espécie de lógica alucinada ou enlouquecida, como a da própria personagem, que só é abandonada na última linha da narrativa, fazendo com que o tema da loucura não seja apenas "desenvolvido" ou "abordado", mas também funcione, em certo sentido, como o próprio princípio da composição.

Para se alcançar tal efeito, certamente é determinante o uso preferencial de elementos tradicionalmente ligados ao texto poético, como o uso de imagens de fundo metafórico - trata-se de uma menina que bebe do orvalho das folhas, derrama copos de água em um limoeiro e que certa vez lavou uma criancinha morta -, imagens que colaboram para a criação do ambiente mágico da narrativa e que só alcançam sentido lógico, como já mencionado, com a revelação final da loucura da menina.

Por outro lado, tudo é composto com a prevalência da parataxe, em detrimento de uma articulação discursiva cerrada e coerente. Fundamental, nesse sentido, é a recorrência da repetição, que, funcionando como uma espécie de refrão, vai "amarrando" os parágrafos da primeira parte da narrativa. Os três primeiros parágrafos se distribuem como estrofes, tal como se pode perceber pela transcrição de suas frases finais:

Que pensamento a dirige para a sombra da mangueira coberta de amarelos e de vermelhos frutos?

[...] vai num enlevo d'alma incompreensível buscar a sombra da mangueira coberta de amarelos e de vermelhos frutos.

8. Sobre os conceitos de maravilhoso e estranho, bem como para sua distinção, cf. TODOROV. A narrativa fantástica. 


\section{$[\ldots]$}

E tão só e pensativa vai em procura da sombra da mangueira coberta de amarelos e vermelhos frutos.

Mais adiante, o oitavo parágrafo faz a recolha e estende a coerência interna: "Mas onde vai a tais horas a menina, pensativa e só, procurando a sombra da mangueira altiva, que enche os ares com a copa de sua folhagem viçosa, coberta de amarelos e vermelhos frutos?".

Nova repetição ocorre no segundo parágrafo da segunda parte do texto, voltando a imagem da menina a caminho da mangueira, espécie de laço de organização entre as duas primeiras partes do texto: "E, de tão infeliz que era, ia todos os dias nas horas calmas à procura da sombra das mangueira". ."

O parágrafo seguinte se inicia com uma apóstrofe que pode ser lida como um verso de sete sílabas: "Carlotinha, Carlotinha" ("porque não te alegras com as meninas da vizinhança, que vão à missa aos domingos e voltam contentes [...]?"). A estrutura se repete dois parágrafos à frente: "Carlotinha, Carlotinha"; ("porque não choras como aqueles, que sofrem, e no pranto encontram alívio às mágoas do coração?"), para em seguida a segunda parte se fechar com um parágrafo que retoma a imagem: "Mas a menina não chora e nem ri; tão só e pensativa procura sempre a sombra da mangueira".

O procedimento, portanto, garante um tipo de encadeamento que reconhecemos ser mais poético que propriamente narrativo, levando, de modo coerente e coeso, a história até a terceira parte, em que se dá o desenlace.

Nessa última parte do texto, desaparecem as repetições e aparecem imagens novas, ainda incongruentes, passando-se a recompor um ambiente mágico, mas, dessa vez, cheio de maus presságios: cai a tarde, ouve-se o canto do acauã; reaparece a menina, molhando as raízes de um limoeiro e revolvendo nas mãos uma conchinha rosa que o irmão (que sabemos morto) lhe dera; à noite, ela brinca com uma borboleta escura e seca; na madrugada, ela sai e procura as roseiras no terreiro, que, todavia, estão mortas, os galhos duros,

9. Frases finais, respectivamente, dos três primeiros parágrafos da narrativa (BRAGA. Carlotinha da mangueira, p. 113).

10. BRAGA. Carlotinha da mangueira, p. 114.

11. BRAGA. Carlotinha da mangueira, p. 116.

12. BRAGA. Carlotinha da mangueira, p. 116.

13. BRAGA. Carlotinha da mangueira, p. 116-117. 
as folhas murchas. Apesar da ilogicidade, o encadeamento fica garantido pela marcação da passagem do tempo: tarde, noite, madrugada, até chegarmos à manhã ensolarada em que se dá o desfecho:

Ao nascer do sol estava Carlotinha encostada ao tronco da mangueira, imóvel, inteiriçada e fria, tão fraca e branca, tão triste e linda, que fazia dó o ver-se-a, e o coração se apertava. O primeiro raio do sol, beijando a boca da menina, vibrou nela um som fraquinho e harmonioso; de todo o seu corpo despreendeu-se a música suave do vento a bater nas folhas da anêmone, e, quando a procuraram nas horas calmosas do dia [repetição de alguns elementos dos primeiros parágrafos], viram-na morta e encostada ao tronco da mangueira.

No dia seguinte, falava-se e dizia-se que Carlotinha, a doida, tinha cessado de sofrer.

A cena, trágica e apelativa, recebe, entretanto, tratamento equilibrado: à elaboração de uma imagem poética - a delicada e quase imperceptível metamorfose da menina em flor e em som, imagem como a se dissolver no ar - segue-se a fria explicação lógica, restabelecendo-se o desejável distanciamento da perspectiva narrativa na última e breve frase do texto.

Enfim: a forte unidade da narrativa, a articulação perfeita entre tema e forma, bem como o cuidadoso e controlado tratamento da linguagem, na busca do efeito da poetização da prosa, tudo faz com que a narrativa de "Carlotinha da mangueira”, superando os modelos sentimentalistas e melodramáticos então em voga, realize-se como um legítimo conto romântico.

14. BRAGA. Carlotinha da mangueira, p. 117. 
Variations of the Romantic short story in Brazil: the poetic prose of "Carlotinha da mangueira", by Gentil Braga

\begin{abstract}
This paper analyzes "Carlotinha da mangueira", by the poet Gentil Homem de Almeida Braga, from the state of Maranhão, bearing in mind the use of poetic procedures. This brief commentary also signals the possibility of admitting the existence of a properly Romantic tradition in the history of modern Brazilian short stories.

Keywords: Brazilian literature, Romantic short stories, "Carlotinha da mangueira".
\end{abstract}

$$
\text { Referências }
$$

BRAGA. Carlotinha da mangueira. In: CAVALHEIRO, Edgard (Sel.). O conto romântico. Introdução e notas de Mário da Silva Brito. Rio de Janeiro: Civilização Brasileira, 1961. p. 113-117. (Panorama do conto brasileiro, 2).

BRITO, Mário da Silva. Nota introdutória. In: CAVALHEIRO, Edgard (Sel.). O conto romântico. Introdução e notas de Mário da Silva Brito. Rio de Janeiro: Civilização Brasileira, 1961. p. 1-8. (Panorama do conto brasileiro, 2).

CAVALHEIRO, Edgard (Sel.). O conto romântico. Introdução e notas de Mário da Silva Brito. Rio de Janeiro: Civilização Brasileira, 1961. (Panorama do conto brasileiro, 2).

LIMA, Herman. Variações sobre o conto. Rio de Janeiro: MEC, 1952.

LIMA SOBRINHO, Barbosa (Introd., pesquisa e seleção). Os precursores do conto no Brasil. Rio de Janeiro: Civilização Brasileira, 1960. (Panorama do conto brasileiro, 1).

MONTELLO, Josué. O conto brasileiro: de Machado de Assis a Monteiro Lobato. Rio de Janeiro: Edições de Ouro, 1967.

TODOROV, Tzvetan. A narrativa fantástica. In: Paulo: Perspectiva, 1971. p. 147-167. As estruturas narrativas. São 